\title{
Scantling Optimization of Ship Structures Considering Fatigue at the Early Design Stage
}

\author{
A. AMRANE, P. RIGO \\ ANAST - University of Liège, Chemin des chevreuils, 1, 4000 Liège, Belgium
}

\begin{abstract}
Fatigue aspects are leading criterion for the scantling optimization of ships structures. LBR-5 software is an integrated package which performs, at the early design stage, cost and/or weight optimization of ships structures (scantling). This software takes into account structural constraints (yielding, buckling, displacement, ultimate strength). Until now, the fatigue failure issue was not implicitly included in the optimization loop. At the early design stage, limited information and details are available. Therefore simplified methods have to be applied. LBR-5 software provides the nominal stress, so chosen procedure uses the nominal stress and the Miner's rule. This approach requires a library of stress concentration factors for predefined typical structural details. The goal of the present work is to develop a tool for fatigue assessment that can be integrated on LBR5 optimization process, to realize global optimization taking into account the fatigue issues. Until now, the integration of the fatigue tool is not finished. Only fatigue verification on the optimized structure is possible. On the present paper, the procedure adopted is presented and a longitudinal scantling of the mid-ship section of a LNG is optimized with LBR-5. Production cost is considered as objective functions. The optimized scantling is checked by the fatigue tool. The fatigue criterion is not respected on some panels. Corrections are performed on these panels to have an optimized scantling without fatigue problems.
\end{abstract}

Keywords: Fatigue, Scantling optimisation, Multi-criteria optimisation, Multi-objective optimisation, LNG carriers, Shipbuilding, early design stage, amidships section

\section{LBR-5 PRESENTATION}

LBR-5 is the French acronym of "Stiffened Panels Software" version 5.0. This software is an integrated package which performs, at the early design stage, cost and/or weight of stiffened ship structures, allowing:

- linear 3D analysis of prismatic structures (generally a cargo hold),

- the calculation of the most relevant limit states of the structure in an analysis based on the general solid-mechanics,

- optimization of the scantlings (plate thickness, profile sizes, dimensions and spacing),

- including the unit construction costs and the production sequences in the optimization process (through a production-oriented cost objective function).

LBR5 uses an analytical method (based on differential equations of stiffened plates) to compute the overall response of the hull structure, Rigo (2005).
This method is a direct analysis of the stress and strain of the prismatic part of the ship or a cargo hold. LBR5 methodology for the response calculation can be summarized as follows:

- Primary and secondary stresses

- Direct analysis of the stress and strain of the prismatic part of the ship or a cargo hold or a midship section.

o Primary stress (longitudinal) due to hull bending moment

- Secondary stress (transverse bending of frames) due to waves and cargo

- Tertiary stress

$\circ$ plate bending (simplified model - Hughes approach, Hughes (1983)

o stiffener bending (simplified model - beam model)

LBR5 allows considering and assessing the structural constraints: yielding, buckling, displacement and ultimate strength. Until now, the fatigue failure 
issue was not implicitly included in the optimization loop.

With LBR5, only the prismatic (cylindrical) part of the ship structure can be investigated and optimized. Generally, the model is limited by two transversal bulkheads (or cofferdams). The hull is divided in several interconnected panels (elements), considered simply supported by the bulkheads. Figure 1 shows a typical LBR-5 stiffened cylindrical shell element and a typical stiffened plate element.

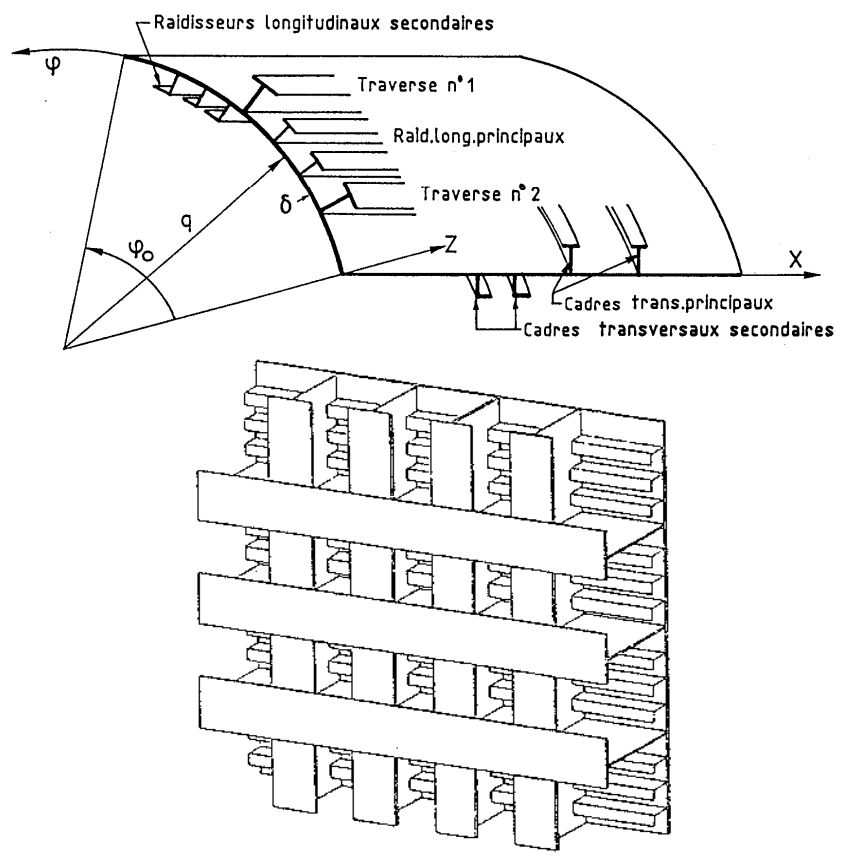

Figure 1. Stiffened cylindrical shell and plate element for LBR5.

LBR-5 is composed of 3 basic modules (OPTI, CONSTRAINT and COST), (Rigo 2001, Rigo \& Fleury 2001). The user selects the relevant constraints (geometrical and structural constraints) in external databases. When the optimization deals with least construction costs, unitary material, welding, cutting and labor costs must be specified by the user to define an explicit objective function (not empirical). For least weight, these unitary costs are not used and the objective function depends only on the geometrical parameters. Using all these data (constraints, objective function and sensitivity analysis), the optimum solution is found using an optimization algorithm CONLIN based on a convex linearization of the non-linear functions (constraints and objective functions) and on a dual approach, (Fleury \& Braibant 1986, Rigo \& Fleury 2001). Independent of the number of design variables and constraints, the number of iterations requiring a complete structural re-analysis is limited to 10 or 15 .

For each panel one can associate up to 9 design variables (XI). These 9 design variables are respectively:
- Plate thickness,

- For longitudinal members (stiffeners, crossbars, longitudinals, girders, etc.):

- web height and thickness,

- flange width,

- spacing between 2 longitudinal members.

- For transverse members (frames, transverse stiffeners, etc.):

- web height and thickness,

- flange width,

- spacing between 2 transverse members (frames).

Since 1980 the FEM has become a standard to evaluate constraints on stress, displacement and ultimate strength at each iteration. With FEM, structure analysis of a large structure is quite demanding and thus represents the major portion of computing time. LBR-5 does not have the capability of a finite element analysis and is restricted to prismatic structures and linear 3D analysis. But, on the other hand, LBR-5 uses explicit exact first order sensitivities (derivatives of the constraint and objective functions by the hundreds of design variables). Heavy and time consuming numerical procedures are not required. Sensitivities are directly available as the method is based on an analytic solution of the differential equations of cylindrical stiffened plates using Fourier series expansions. So, sensitivity formulations are known analytically. Due to the efficient CONLIN mathematical optimization algorithm (convex linearization and dual approach), optimization of the full structure can be performed with hundreds of design variables and constraints using less than 10-15 global structure re-analysis (iterations).

\section{FATIGUE BACKGROUND}

Crack propagation and fatigue aspects are leading criterion for the scantling optimization of ships and FPSO structures, which are submitted to cycling loading-unloading operations. Fatigue damage is an extremely localized phenomenon.

In particular, the welded joints are regions of weakness in a structure for their low fatigue strength, due to the presence of crack-like defects, high stress concentration effects, and tensile residual stress fields caused by thermal expansion.

In general, there are several approaches for fatigue assessment. In Figure 2, (Radaj et al., 2006), the most important basic variants of the methods are plotted. The simplest approach is the Nominal stress approach. It necessitates only the knowledge of the main dimension of the structure. But it's not very efficient when we consider real complex 
structures. On those situations, other methods more relevant can be used. These methods are structural hot-spot stress and notch stress approaches. The fracture mechanics approaches with J-integral or stress intensity factors are not commonly used due to the extremely time-consuming structural analysis.

Nominal stress is the stress calculated in general utilizing elementary theories of structural mechanics based on linear-elastic behaviour (beam or plate theory) or coarse mesh FEM in the sectional area under consideration, taking into account the stress raising effects of the macro geometric shape of the component in the vicinity of the joint buy disregarding the local stress raising effects of the welded joint, such as e.g. large cut-outs. Overall elastic behaviour is assumed. The Hot Spot stress is a local stress at the hot spot taking into account the influence of structural discontinuities due the geometry of the connexion but excluding the effect of the weld. The notch stress is the total (peak) stress that we found at the notch (toe of the weld, edge of cut out,...). Additionally to all the affects considered by the hot spot stress, the notch stress considers the effects of the weld.

The S-N curves are the most common way to represent the capacity of the structure. It gives the relationship between the nominal stress ranges " $S$ " and the fatigue life or number of cycles to failure N. Fatigue cracks in welded structures appear on the welded joints or flame-cut edges. S-N curves are therefore given for welded joints and flame-cut edges. The fatigue strength of structure is assessed by evaluation of fatigue damage ratio. The damage sum is calculated using a linear cumulative damage theory and Palmer-Miner rule.

\section{PRESENTATION OF THE PROCEDURE ADOPTED}

Due to the complexity of the ship structural details, the notch stress approach is chosen. The notch stress method can cover different structural geometries and details defining fatigue strength with one design curve.

The fatigue module has to be linked with LBR-5 software to calculate, at the early stage design, the fatigue damage on critical connections of the ship structures. LBR-5 software provides only the nominal stress. The hot spot stress will be calculated by multiplying the nominal stress by a hot spot stress concentration factor. In similar way, the notch stress can be calculated by multiplying the hot spot stress by a notch factor.

The S-N curve considered is derived from Bureau VERITAS rules (1998), for non-tubular joints in the as-rolled condition with no flame cut edges and correspond to the curve B provided by the U.K. department of Energy (1993). This basic curve is corrected to take into account the influence of static and residual stress, the effect of compressive stress, the influence of thickness and the Haibach effect.

\subsection{Fatigue-critical locations in ship structures}

Even if LBR5 software don't consider the entire ship structure (only the prismatic (cylindrical) part at the mid-ship structure), a big amount of fatigue crack occurs on this area. So, generally, maximum stress is situated in this area because the hull girder moment is maximum there.

A lot of Structural details and connections are similar between different ship types. But, there are some special structural details witch depend on the ship type.

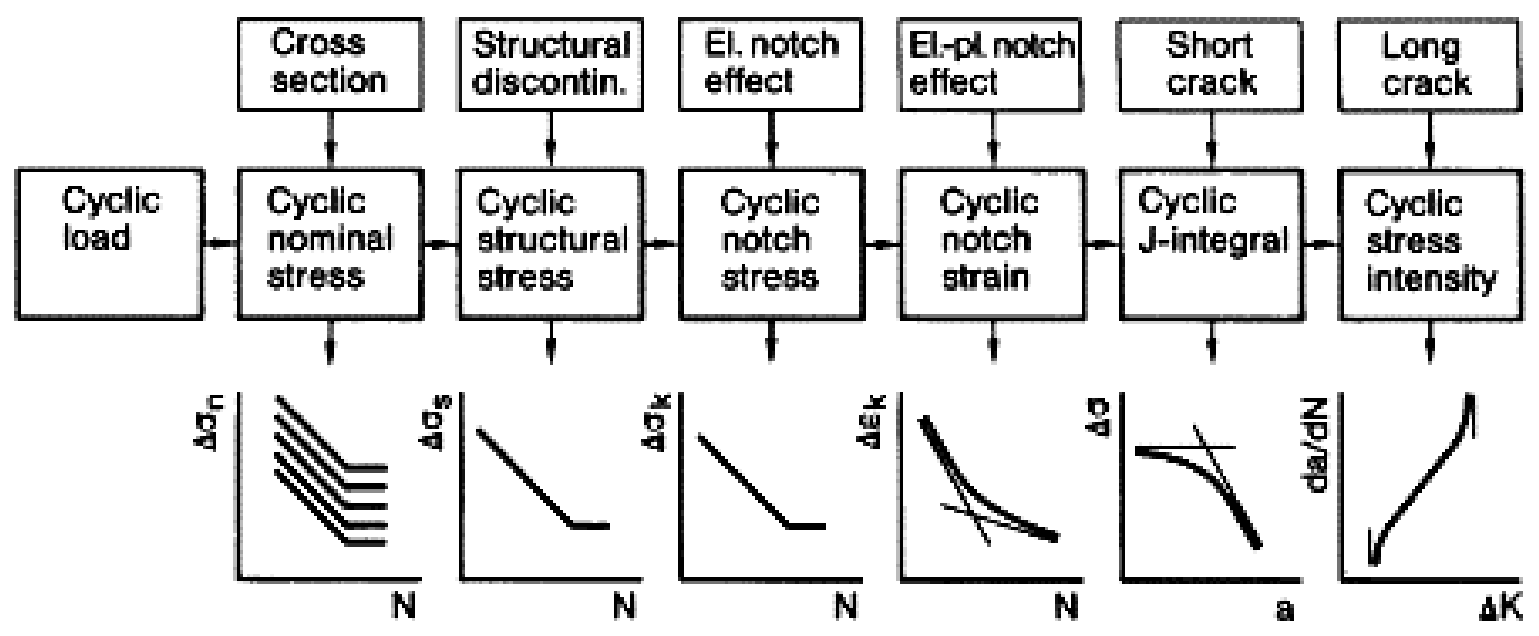

Figure 2: Method for fatigue assessment, (Radaj et al., 2006) 
In general, fatigue cracks are observed on geometrical discontinuities, such as connection between longitudinal and transverse structures.

The end of longitudinal stiffeners, particularly brackets and cut-outs are critical details. Connections between stiffened plates, for example at the hopper tank in LNG carriers and cofferdam area is also critical.

Additionally, on some cases, the ends of pillars, girders and web frames are fatigue-critical.

\subsection{Calculation of stresses at critical locations}

The stress evaluation is performed within the LBR5 software. So, it's important to extract the relevant stress for each critical detail.

Depending of the method chosen to perform the fatigue assessment, three kinds of stresses have to be taken into account: nominal stress, structural hotspot stress and notch stress, Figure 3.

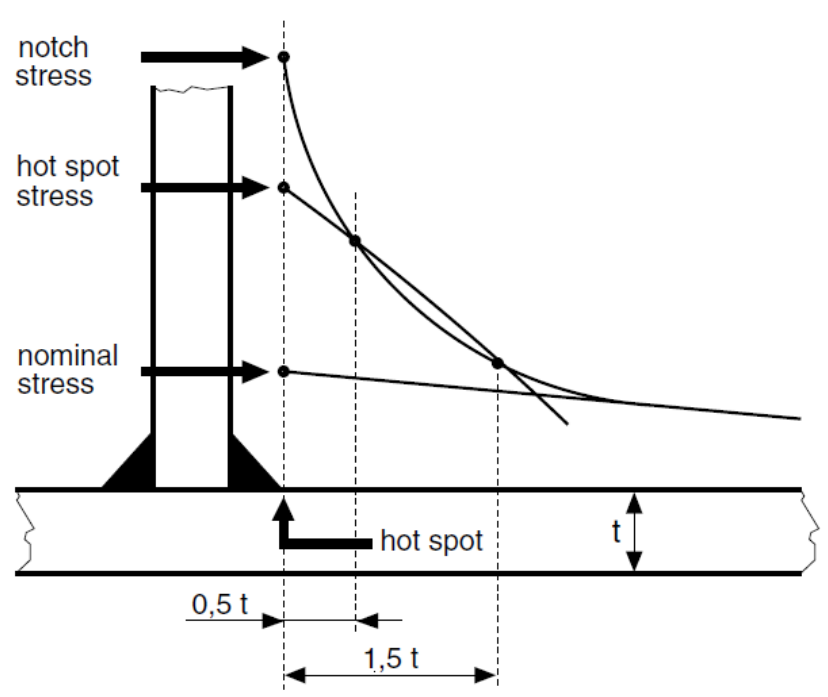

Figure 3: Nominal, hot spot and notch stresses, Bureau VERITAS (2009a)

\subsubsection{Nominal stress}

For fatigue-critical structural details nominal stress to be considered are the principal stresses at the hot spots which form the smallest angle with the crack rising surface. The relevant stress components depend on critical detail considered.

The number of critical details is relatively large. So it's necessary to gather these details into categories to obtain a generic approach for the early design stage.

The critical details are divided into 5 categories:

$>$ Critical details situated at the connections of longitudinal ordinary stiffeners with transverse primary elements

Critical details situated on the plates connections
Critical details situated at the plate / frames connections

Critical details situated at frames flanges

Critical details situated at the girders flanges

Of course, other details categories will be added to this list on the future.

The relevant nominal stresses associated with each detail category are described on the following paragraphs.

3.2.1.1 Connection of longitudinal ordinary stiffeners with transverse primary elements

The critical hot spots are shown on Figure 4. The nominal stress at the hot-spot point is the normal stress which is perpendicular to the weld seam. In this case, the maximum principal stress is equal to the normal stress.

$\sigma_{\text {nominal }}=\left|\sigma_{\mathrm{h}}+\sigma_{1}\right|$

$\sigma_{\mathrm{h}}$ : Nominal hull girder on the flange of the stiffener

$\sigma_{1}$ : Nominal local stress on the flange of the stiffener

3.2.1.2 Critical details situated on the plates connections

On the plate, there is biaxial stress state. LBR5 software can provide normal and shear stresses on both directions and on top and bottom surfaces of the plate. So, the stress to consider is the principal stress which is approximately in line with the perpendicular to the weld toe, i.e. within a deviation of $\pm 60^{\circ}$. According to IIW recommendations, Hobbacher (2007), see Figure 6.

$\sigma_{n o \min a l}=\max \left(\left|\sigma_{1}\right|,\left|\sigma_{2}\right|\right)$

Where $\sigma_{1}$ and $\sigma_{2}$ are principal stresses

$$
\begin{aligned}
\sigma_{1,2}= & \frac{\sigma_{x(\text { plate })}+\sigma_{y(\text { plate })}}{2} \\
& \pm \sqrt{\left(\frac{\sigma_{x(\text { plate })}-\sigma_{y(\text { plate })}}{2}\right)^{2}+\tau_{x y(\text { plate })}^{2}}
\end{aligned}
$$

The $\sigma_{x \text { (plate) }}, \sigma_{y \text { (plate) }}$ and $\tau_{x y \text { (plate) }}$ are normal and shear stresses at top or bottom surface of the deck plate. 
3.2.1.3 Critical details situated at the plate / frames connections

Lot of cracks may initiate on plate/frames connections. The stress to be considered is the maximum is the principal stress at the hot spot.

$$
\sigma_{n o \min a}=\max \left(\left|\sigma_{1}\right|,\left|\sigma_{2}\right|\right)
$$

Where $\sigma_{1}$ and $\sigma_{2}$ are principal stresses

$$
\sigma_{1,2}=\frac{\sigma_{x(\text { plate })}+\sigma_{y(\text { plate/ frame })} \pm}{2} \sqrt{\left(\frac{\left.\sigma_{x(\text { plate })}-\sigma_{y(\text { plate / frame })}\right)^{2}+\tau_{x y(\text { plate/ frame })}^{2}}{2}\right.}
$$

The $\sigma_{x(\text { plate })}$ is normal stresses at top or bottom surface of the deck plate at the intersection with the frame, see Figure 6.

$\sigma_{y \text { (plate/frame) }}$ and $\tau_{x y \text { (plate/frame) }}$ are normal and shear stresses at frame web/plate junction.

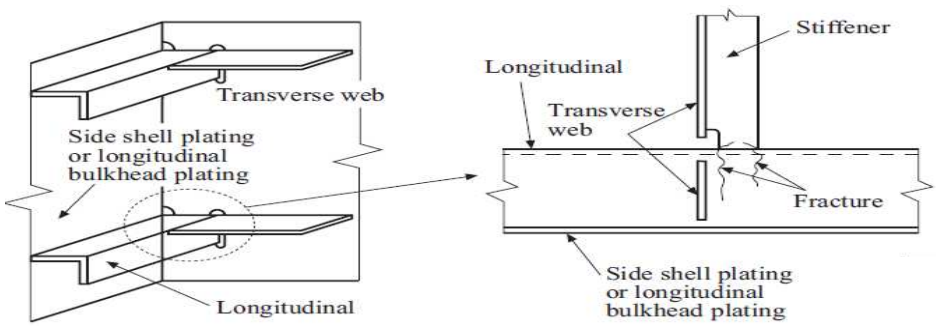

Figure 4: Typical connection of longitudinal ordinary stiffeners with transverse primary elements, GERMANISCHER Lloyd (2007)
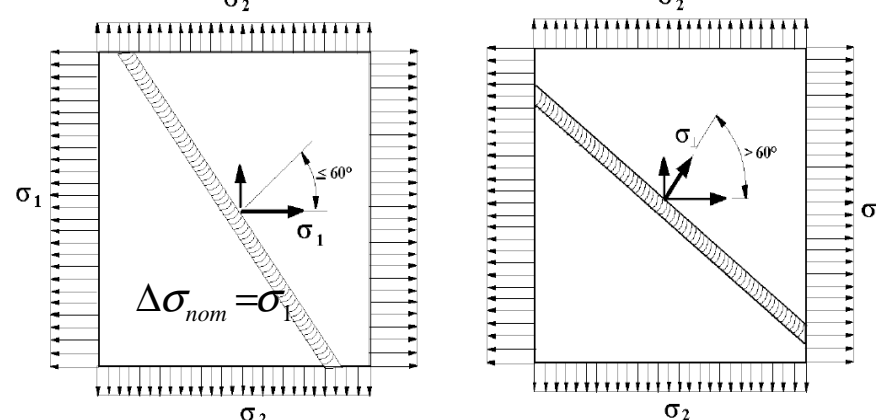

Figure 5: Biaxial stress at weld toe, Hobbacher (2007).

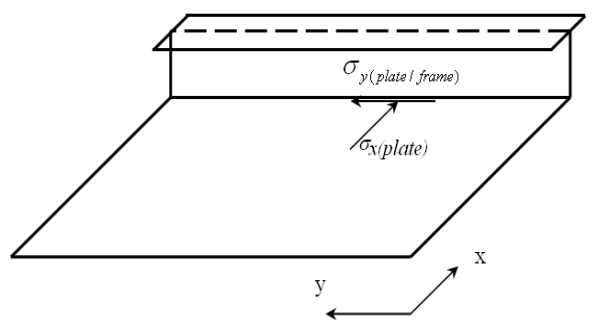

Figure 6: stresses on plate / frames connections

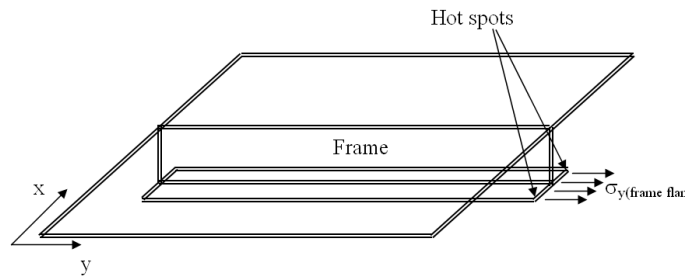

Figure 7: stresses on frames ends

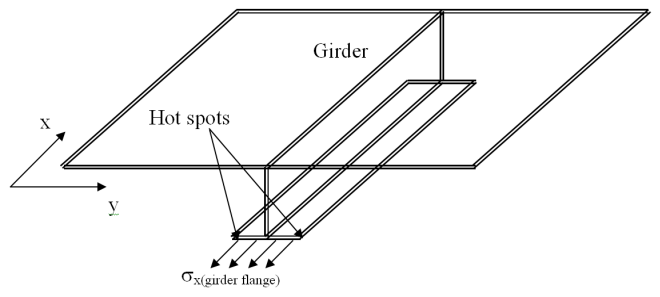

Figure 8: stresses on girders ends

\subsubsection{Critical details situated at frame flange}

In certain cases, the ends of frames can be a critical areas. The hot spots are situated on the frame flanges (Figure 7). The nominal stress is equal to the normal stress on the frame.

$$
\sigma_{\text {nominal }}=\sigma_{y(\text { frame flange })}
$$

\subsubsection{Critical details situated at the girders}

For the ends of girder, the hot spots are situated on the girder flange (Figure 8). The nominal stress is equal to the normal stress on the flange of the girder.

$$
\sigma_{\text {nominal }}=\sigma_{y(\text { Girder flange })}
$$

\subsubsection{Hot spot stress}

After calculating the nominal stress on the critical locations, the structural hot-spot stress range $\Delta \sigma_{h s}$ is defined using hot-spot stress concentration factor $K_{G}$.

$$
\Delta \sigma_{h s}=\Delta \sigma_{n o \min a l} \cdot K_{G},
$$

The value of the hot-spot stress concentration factor depends on the type of detail. This approach adopted requires a library of stress concentration factors for predefined typical structural details. Values of some critical locations based on literature review (Bureau VERITAS 1998, 2009b, D.N.V.2005, Remes et al. 2009) are presented on Table 1 . The values can be updated in the future based on parametric FE -analysis. The user can also modify and add new details to the library. 
Table 1: Hot-spot stress concentration factor $K_{G}$.

\begin{tabular}{|c|c|c|}
\hline Description of joint & Configuration & $\begin{array}{l}\text { Concentration } \\
\text { factor }\end{array}$ \\
\hline \multirow{2}{*}{$\begin{array}{l}\text { Connection of longitudinal ordinary stiffeners } \\
\text { with stiffeners of transverse primary support- } \\
\text { ing members - No bracket }\end{array}$} & & $\begin{array}{l}\text { with non-watertight collar plate: } \\
\qquad K_{G}=1.8\end{array}$ \\
\hline & $\underline{\|}$ & $\begin{array}{l}\text { with full collar plate (watertight): } \\
\qquad K_{G}=1.7\end{array}$ \\
\hline $\begin{array}{l}\text { Connection of longitudinal ordinary stiffeners } \\
\text { with stiffeners of transverse primary support- } \\
\text { ing members - With bracket }\end{array}$ & & $\begin{array}{l}\text { with non-watertight collar plate: } \\
\qquad K_{G}=1.65\end{array}$ \\
\hline $\begin{array}{l}\text { Critical details situated on the plates connec- } \\
\text { tions }\end{array}$ & & $K_{G}=1.8$ \\
\hline $\begin{array}{l}\text { Critical details situated at the plate / frames } \\
\text { connections }\end{array}$ & & $K_{G}=1.8$ \\
\hline $\begin{array}{l}\text { Critical details situated at frames and girders } \\
\text { flanges- No bracket }\end{array}$ & & $K_{G}=1.9$ \\
\hline $\begin{array}{l}\text { Critical details situated at frames and girders } \\
\text { flanges- Vertical bracket }\end{array}$ & & $K_{G}=1.7$ \\
\hline $\begin{array}{l}\text { Critical details situated at frames and girders } \\
\text { flanges- Horizontal bracket }\end{array}$ & & $K_{G}=1.65$ \\
\hline $\begin{array}{l}\text { Critical details situated at frames and girders } \\
\text { flanges- Rounded horizontal bracket }\end{array}$ & & $K_{G}=1.5$ \\
\hline
\end{tabular}




\subsubsection{Notch stress}

The notch stress range can be from the following formula, Bureau VERITAS (1998):

$$
\Delta \sigma_{\text {notch }}=0.7 \cdot K_{F} \cdot \Delta \sigma_{h s},
$$

$K_{F}$ is the notch stress concentration factor. Its value depends on the weld geometry and shape.

For flame-cut edges, it depends on the cutting quality, post treatment and control quality.

For welded elements, the fatigue notch factor, equal to:

$k_{F}=\lambda \cdot \sqrt{\frac{\theta}{30}}$,

$\lambda$ : Coefficient depending on the weld configuration, and given in Bureau VERITAS (2009a), Pt B, Ch 7, Sec 4.

$\theta$ : Mean weld toe angle, in degrees, without being taken less than $30^{\circ}$. Unless otherwise specified, $\theta$ may be taken equal to:

- $30^{\circ}$ for butt joints

- $45^{\circ}$ for $\mathrm{T}$ joints or cruciform joints

For flame-cut edges, $\mathrm{K}_{\mathrm{w}}$ may be taken equal to the values defined in Table 2 , depending on the cutting quality, post treatment and control quality;

Table 2: Fatigue notch factor for flame-cut edges, Bureau VERITAS (2009a)

\begin{tabular}{|l|l|}
\hline Flame-cut edge description & $\mathrm{K}_{\mathrm{F}}$ \\
\hline $\begin{array}{l}\text { Machine gas cut edges, with subsequent ma- } \\
\text { chining, dressing or grinding }\end{array}$ & 1,4 \\
\hline $\begin{array}{l}\text { Machine thermally cut edges, corners re- } \\
\text { moved, no crack by inspection }\end{array}$ & 1,6 \\
\hline $\begin{array}{l}\text { Manually thermally cut edges, free from } \\
\text { cracks and severe notches }\end{array}$ & 2,0 \\
\hline $\begin{array}{l}\text { Manually thermally cut edges, uncontrolled, } \\
\text { no notch deeper than } 0,5 \mathrm{~mm}\end{array}$ & 2,5 \\
\hline
\end{tabular}

\subsubsection{Fatigue damage}

The damage sum is calculated using a linear cumulative damage theory and Palmer-Miner rule, Bureau VERITAS (2009a):

$$
\mathrm{D}=\frac{\mathrm{N}}{\mathrm{K}_{\mathrm{P}}} \cdot \frac{\Delta \sigma_{\text {notch }}^{3}}{\left(-\ln \left(\mathrm{p}_{\mathrm{R}}\right)\right)^{3 / \xi}} \cdot \mu \cdot \Gamma_{\mathrm{C}}\left(1+\frac{3}{\xi}\right)
$$

$\Delta \sigma_{\text {notch }} \quad$ Notch stress range

$\xi \quad$ Weibull shape parameter.

$\mu \quad$ coefficient taking into account of the change in slope of the S-N curve

$\Gamma_{c} \quad$ Complete Gamma function

The Weibull distribution witch is defined by the Weibull shape parameter $\xi$, is used as a probability density function to describe the long term stress distribution. The two slope $\mathrm{S}-\mathrm{N}$ curve is defined by the Constant Kp.

Ship structures are subjected to various types of fluctuating loads. For fatigue assessment, the main critical loads are induced by the wave action. The fatigue loadings (moments and pressures) were defined in LBR5 software by an automatic transfer of the fatigue loads calculated by Bureau Veritas Rules from MARS software (BV) to LBR5 optimization tool.

On the ship's life, many loading conditions may occur. However, many ships are navigating most of their life on two loading conditions: full loaded and ballast loading conditions. Consequently, unless specific situations, fatigue analysis may be limited to full loaded and ballast loading conditions.

With each loading condition, four Load cases "a", "b", "c" and "d" are associated. Each load case represents a combination of hull girder loads, external sea pressures and internal inertial and fluctuating loads, Bureau VERITAS (2009a).

For each load case, the damage is calculated (equation (11)) and then a total damage is calculated by the combination of damage of each load case, like following described on Bureau VERITAS (2009a), Pt B, Ch 7, Sec 4 .

\section{TEST AND VALIDATION}

The fatigue tool as described before calculates the fatigue damage by using the stress calculated by the LBR5 software. To be involved on the optimization process, it implies:

- to calculate sensitivities of the Fatigue module to the LBR5 design variables;

- $\quad$ to integrate these into LBR-5;

- to validate the integration by executing several tests;

Until now, this work is not finished. Only fatigue verification on the optimized structure is possible.

A longitudinal scantling of the midship section of a LNG is chosen to perform the optimization with

where 
LBR-5. Production cost is considered as objective function.

One central tank is considered in all analysis. The structure is symmetrical, and for facility reasons only half of the tank is modelled. The tank has a length of 40.5 meters. A 3D view of the model is presented in Figure 9.

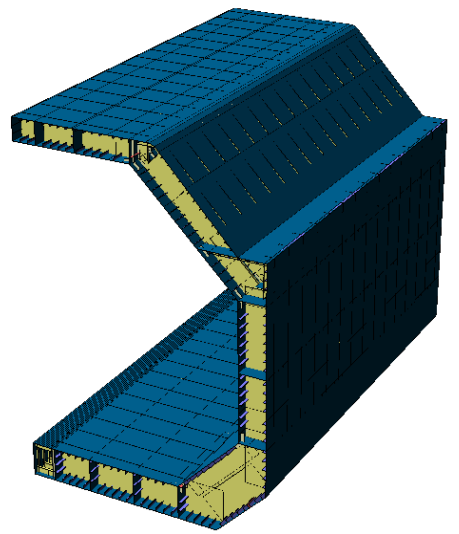

Figure 9 - 3D view of the "Standard" design

The initial scantling is characterized by a weight of $18054.74 \mathrm{kN}$ and a cost of $3164759.61 €$. These values are considered for a half of tank having 40.5 $\mathrm{m}$ of length.

Before optimization, we have the next weights:

- the net weight

$$
\begin{aligned}
=16715.12 \mathrm{kN} \\
=906.11 \mathrm{kN} \\
=17621.24 \mathrm{kN} \\
=18054.74 \mathrm{kN}
\end{aligned}
$$

- the corrosion weight

- the gross weight

- total weight

The total cost estimated is $3164759.61 €$.

First, an optimization is performed without taking into account fatigue. Different structural constraints were used (Von Mises stress $\leq 175 \mathrm{MPa}$, ultimate strength of the beam column, plate thickness yielding / buckling and sloshing constraints). Also, Geometrical (Plate thickness $\leq 2 \mathrm{x}$ stiffener web thickness,...) and equality (All web-frame spacing is equal,...) constraints are imposed. The technological limits used for the optimization are shown in the Table 3.

Table 3 - Technological limits

\begin{tabular}{ccc}
\hline Variable & $\begin{array}{c}\text { Lower Limit } \\
{[\mathrm{mm}]}\end{array}$ & $\begin{array}{c}\text { Upper Limit } \\
{[\mathrm{mm}]}\end{array}$ \\
\hline Plate Thickness & 6 & 25 \\
Frames Web Thickness & 5 & 20 \\
Frames Spacing & 1000 & 3500 \\
Stiffeners Web Height & 80 & 460 \\
Stiffeners Web Thickness & 5 & 20 \\
Stiffeners Flange Width & 10 & 100 \\
Stiffeners Spacing & 400 & 900 \\
\hline
\end{tabular}

After production cost optimization, the weight of the structure becomes $16627.84 \mathrm{kN}$ and the cost
$3001482.47 €$. Thus, the cost's gain compared to the initial scantling is approximately $5.25 \%$.

Concerning the weight, the next values are found:

- the net thickness

$$
=15313.81 \mathrm{kN}
$$

- the corrosion thickness $=880.52 \mathrm{kN}$

- the gross thickness $\quad=16194.34 \mathrm{kN}$

- total weight$$
=16627.84 \mathrm{kN}
$$

After optimization, the optimum scanting is used to verify if it respect the fatigue criteria. For fatigue assessment, different panels have been considered:

Connection of side longitudinal ordinary stiffeners with stiffeners of transverse primary supporting members

Connection of bottom longitudinal ordinary stiffeners with floors

Connection of inner bottom longitudinal ordinary stiffeners with floors

Connection of inner bottom with transverse cofferdam bulkheads

Connection of inner bottom with hopper tank sloping plates

Connection of hopper tank sloping plates with inner side plates

A comparison is done in order to validate the fatigue results obtained with LBR- 5 code by FE results using VeriSTAR software provided by Bureau VERITAS (Figure 10, Figure 11 and

Figure 12). For the early design stage, the results of LBR5 are acceptable.

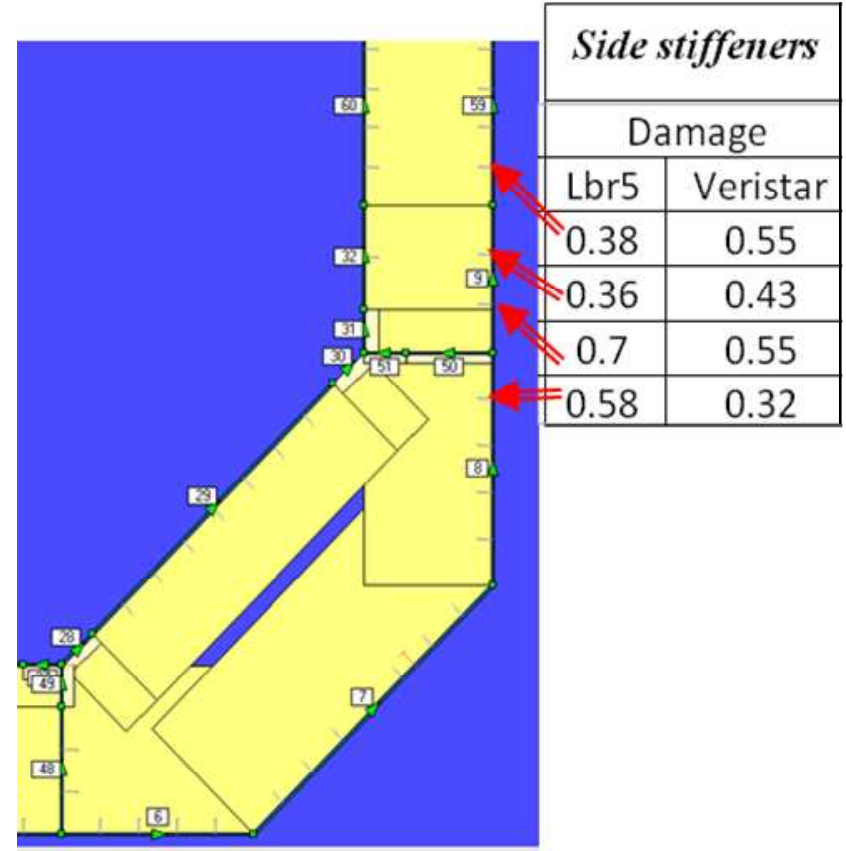

Figure 10 - Comparison LBR5 / VeriSTAR: stiffeners

On Table 4, are presented the damage of: the scantling before optimization;

- the scantling after optimization without fatigue constraints; 
- the scantling after optimization after fatigue

corrections to avoid fatigue damage

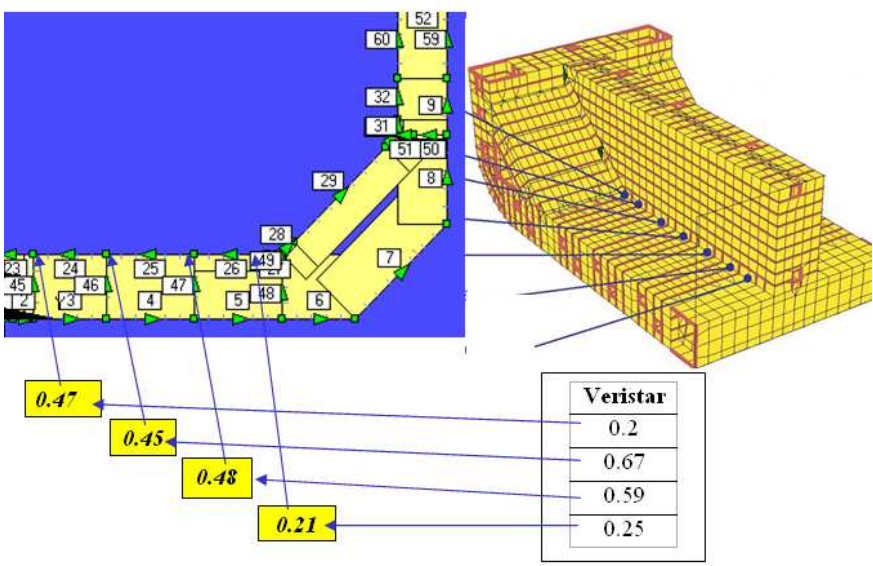

Figure 11 - Comparison LBR5 / VeriSTAR: intersection inner bottom with cofferdam

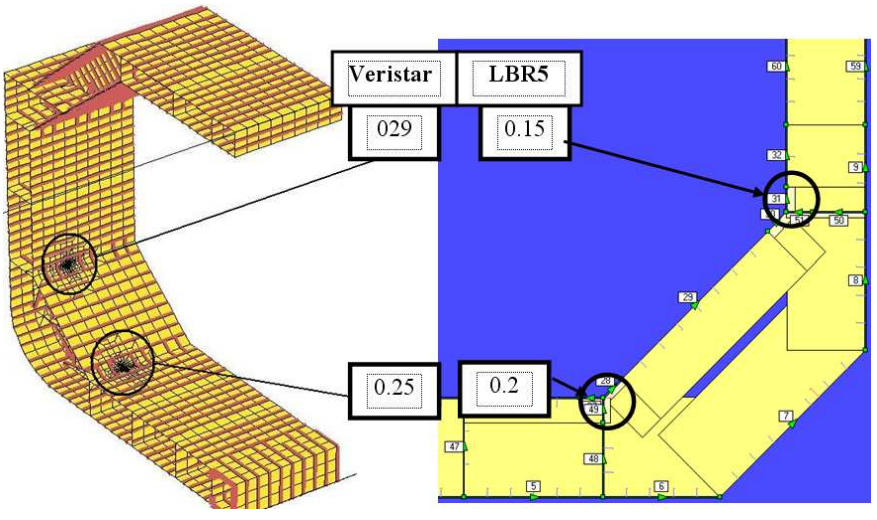

Figure 12 - Comparison LBR5 / VeriSTAR: knuckles

Table 4 - Fatigue damage on the different scantlings

\begin{tabular}{|c|c|c|c|c|c|c|}
\hline & & & & $\begin{array}{l}\text { Before opti- } \\
\text { mization }\end{array}$ & $\begin{array}{l}\text { optimization (without } \\
\text { fatigue constraints) }\end{array}$ & $\begin{array}{c}\text { Optimization } \\
\text { (fatigue corrections) }\end{array}$ \\
\hline & & & & DAMAGE & DAMAGE & DAMAGE \\
\hline \multicolumn{7}{|c|}{ Connection of Bottom stiffeners with floors } \\
\hline Panel & 3 & Departure & Node & 0.44 & 0.40 & 0.38 \\
\hline Panel & 3 & Arrival & Node & 0.41 & 0.37 & 0.36 \\
\hline Panel & 4 & Departure & Node & 0.40 & 0.37 & 0.36 \\
\hline Panel & 4 & Arrival & Node & 0.36 & 0.34 & 0.33 \\
\hline Panel & 5 & Departure & Node & 0.35 & 0.34 & 0.33 \\
\hline Panel & 5 & Arrival & Node & 0.32 & 0.33 & 0.31 \\
\hline Panel & 6 & Departure & Node & 0.32 & 0.31 & 0.30 \\
\hline Panel & 6 & Arrival & Node & 0.37 & 0.36 & 0.35 \\
\hline \multicolumn{7}{|c|}{ Connection of side stiffeners with transversal frames } \\
\hline Panel & 8 & Arrival & Node & 0.58 & 7.60 & 0.76 \\
\hline Panel & 9 & Departure & Node & 0.7 & 0.67 & 0.66 \\
\hline Panel & 9 & Arrival & Node & 0.36 & 0.34 & 0.34 \\
\hline Panel & 59 & Departure & Node & 0.38 & 0.35 & 0.34 \\
\hline \multicolumn{7}{|c|}{ Connection of Inner Bottom stiffeners with floors } \\
\hline Panel & 24 & Departure & Node & 0.43 & 13.46 & 0.65 \\
\hline Panel & 24 & Arrival & Node & 0.49 & 14.06 & 0.73 \\
\hline Panel & 25 & Departure & Node & 0.35 & 12.38 & 0.51 \\
\hline Panel & 25 & Arrival & Node & 0.42 & 13.29 & 0.63 \\
\hline Panel & 26 & Departure & Node & 0.33 & 11.61 & 0.46 \\
\hline Panel & 26 & Arrival & Node & 0.35 & 12.43 & 0.51 \\
\hline \multicolumn{7}{|c|}{ Connection of inner bottom with transverse cofferdam bulkheads } \\
\hline Panel & 24 & Arrival & Node & 0.47 & 1.83 & 0.80 \\
\hline Panel & 25 & Departure & Node & 0.45 & 1.81 & 0.77 \\
\hline Panel & 25 & Arrival & Node & 0.48 & 1.85 & 0.81 \\
\hline Panel & 26 & Departure & Node & 0.21 & 1.92 & 0.83 \\
\hline \multicolumn{7}{|c|}{ Connection of inner bottom with hopper tank sloping plates } \\
\hline Panel & 28 & Departure & Node & 0.21 & 0.20 & 0.19 \\
\hline \multicolumn{7}{|c|}{ Connection of hopper tank sloping plates with inner side plates } \\
\hline Panel & 30 & Arrival & Node & 0.15 & 0.11 & 0.11 \\
\hline
\end{tabular}


On the scantling after optimization without fatigue constraints, there are fatigue problems on the panels $8,24,25,26$. Stresses on those panels increase because plate thicknesses and stiffeners scantlings are decreased after optimization.

Table 5 - Dimensions of the panels with fatigue problems (net scantling)

\begin{tabular}{|c|c|c|c|c|}
\hline $\begin{array}{l}\text { Dimensions } \\
(\mathrm{mm})\end{array}$ & $\begin{array}{c}\text { Before opti- } \\
\text { mization }\end{array}$ & $\begin{array}{l}\text { optimization } \\
\text { (without fatigue } \\
\text { constraints) }\end{array}$ & \multicolumn{2}{|c|}{$\begin{array}{l}\text { Optimization } \\
\text { (fatigue cor- } \\
\text { rections) }\end{array}$} \\
\hline \multicolumn{5}{|l|}{ panel 8} \\
\hline $\begin{array}{l}\text { plate } \\
\text { thickness }\end{array}$ & 17.61 & 13.17 & 13.2 & \\
\hline web height & 305 & 230.7 & 287.2 & \\
\hline $\begin{array}{c}\text { web } \\
\text { thickness }\end{array}$ & 10 & 5.3 & 10.0 & $\underline{\Xi}$ \\
\hline $\begin{array}{l}\text { flange } \\
\text { breath }\end{array}$ & 59 & 92.3 & 55.8 & 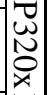 \\
\hline $\begin{array}{c}\text { flange } \\
\text { thickness }\end{array}$ & 35 & 10.7 & 32.8 & $\bar{N}$ \\
\hline \multicolumn{5}{|l|}{ panel 24} \\
\hline $\begin{array}{c}\text { plate thick- } \\
\text { ness }\end{array}$ & 19 & 16.55 & 20.0 & \\
\hline web height & 305 & 182.8 & 287.2 & \\
\hline $\begin{array}{c}\text { web thick- } \\
\text { ness }\end{array}$ & 10 & 6.8 & 10.0 & 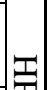 \\
\hline $\begin{array}{l}\text { flange } \\
\text { breath }\end{array}$ & 59 & 80.6 & 55.8 & 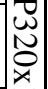 \\
\hline $\begin{array}{c}\text { flange } \\
\text { thickness }\end{array}$ & 35 & 10.3 & 32.8 & $\bar{N}$ \\
\hline \multicolumn{5}{|l|}{ panel 25} \\
\hline $\begin{array}{c}\text { plate } \\
\text { thickness }\end{array}$ & 19 & 16.6 & 20.0 & \\
\hline web height & 305 & 182.8 & 287.2 & \\
\hline $\begin{array}{c}\text { web } \\
\text { thickness }\end{array}$ & 10 & 6.8 & 10.0 & $\Xi$ \\
\hline $\begin{array}{l}\text { flange } \\
\text { breath }\end{array}$ & 59 & 80.6 & 55.8 & 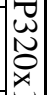 \\
\hline $\begin{array}{c}\text { flange } \\
\text { thickness }\end{array}$ & 35 & 10.3 & 32.8 & $\bar{N}$ \\
\hline \multicolumn{5}{|l|}{ panel 26} \\
\hline $\begin{array}{l}\text { plate } \\
\text { thickness }\end{array}$ & 22 & 16.6 & 20.0 & \\
\hline web height & 305 & 182.8 & 287.2 & \\
\hline $\begin{array}{c}\text { web thick- } \\
\text { ness }\end{array}$ & 10 & 6.8 & 10.0 & 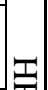 \\
\hline $\begin{array}{l}\text { flange } \\
\text { breath }\end{array}$ & 59 & 80.6 & 55.8 & 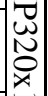 \\
\hline $\begin{array}{c}\text { flange } \\
\text { thickness }\end{array}$ & 35 & 10.3 & 32.8 & $\bar{N}$ \\
\hline
\end{tabular}

Therefore, corrections have to be done on those panels to avoid fatigue cracks. To decrease the damage values, the inertia of the stiffener with the attached plate have to be increased for the hot spots situated on stiffeners. For the hot spots situated on the plates, the plate thickness has to be increased.
By correcting the scantling after optimization process, the value of the production cost is 3015410.64 $€$, and the gain compared to the initial scantling is approximately $4.58 \%$.

Table 6 - Initial, optimized without fatigue constraints and fatigue corrected scantling comparison

\begin{tabular}{|c|c|c|c|c|}
\hline Scantling & $\begin{array}{c}\text { Mass } \\
{[\text { tons }]}\end{array}$ & $\begin{array}{c}\text { Gain in } \\
\text { mass }\end{array}$ & $\begin{array}{c}\text { Cost } \\
{[\mathrm{M} €]}\end{array}$ & $\begin{array}{c}\text { Gain in } \\
\text { cost }\end{array}$ \\
\hline Initial & 1840.44 & & 3.16 & \\
\hline $\begin{array}{c}\text { optimization } \\
\text { (without fatigue } \\
\text { constraints) }\end{array}$ & 1694.99 & $\mathbf{7 . 9 0 \%}$ & 3.00 & $\mathbf{5 . 1 6 \%}$ \\
\hline $\begin{array}{c}\text { optimization } \\
\text { (after fatigue cor- } \\
\text { rections) }\end{array}$ & 1714.13 & $\mathbf{6 . 8 6 \%}$ & 3.02 & $\mathbf{4 . 5 8 \%}$ \\
\hline
\end{tabular}

The correction to avoid fatigue problems increases the cost and weight comparatively to the scantling after optimization process by $0.51 \%$ and $\mathbf{1 . 1 3} \%$ respectively (Table 7).

Table 7 - Optimized without fatigue constraints and fatigue corrected scantling comparison

\begin{tabular}{|c|c|c|}
\hline Scantling & Mass [tons] & $\begin{array}{c}\text { Cost } \\
{[\mathrm{M} €]}\end{array}$ \\
\hline $\begin{array}{c}\text { Optimized (without fa- } \\
\text { tigue constraints) }\end{array}$ & 1694.99 & 3 \\
\hline $\begin{array}{c}\text { Optimized \& Corrected } \\
\text { fatigue }\end{array}$ & 1714.12 & 3.02 \\
\hline difference & 19.14 & 0.02 \\
\hline$\%$ & $1.13 \%$ & $0.51 \%$ \\
\hline
\end{tabular}

Material cost represents the most important part of the increase on the total. This is logical because only the plate thickness and stiffeners scantling was modified.

\section{CONCLUSIONS}

A fatigue tool has been developed in the framework of the IMPROVE Project. A methodology is chosen by taking into account of the capabilities of the LBR5 software and the need to be used early deigns stage. Some tests were performed by comparing the results to the results obtained with VERISTAR software provided by Bureau VERITAS. This comparison shows that the LBR5 results are not perfect and further tests must be performed to calibrate more the fatigue module and to add more critical details on a library of stress concentration factors. The difference of the results compared to VERISTAR can be explained by the fact that LBR5 does not have the capability of a finite element analysis and is restricted to prismatic structures and linear 3D analysis. For the early design stage, the results of LBR5 are acceptable and help the designer to choose the best solution (scantling). The 
remain work is finishing the integration of the fatigue tool inside LBR5 optimization loop.

\section{ACKNOWLEGMENTS}

The authors thank the IMPROVE PROJECT (FP6) and the associated partners as part of the present paper has been developed in the framework of this project.

\section{References}

Bureau VERITAS, 1998. Fatigue strength of welded ship structures. Paris, Bureau Veritas.

Bureau VERITAS, 2009a. Bureau VERITAS rules, Pt B, Ch 7, Sec 4, Paris, Bureau Veritas.

Bureau VERITAS, 2009b. Bureau VERITAS rules Pt B, Ch 12 , Sec 2. Paris, Bureau Veritas.

D.N.V., 2005. Fatigue assessment of ship structures. Classification notes No. 30.7. Hovik, Norway

Fleury, C. \& Braibant, V., 1986. Structural Optimization: a New Dual Method using Mixed Variables. Int J Numer Methods Eng; 23:28.

GERMANISCHER Lloyd, 2007. GERMANISCHER Lloyd rules.

Hobbacher, A., 2007, IIW Joint Working Group XIII-XV. 2007.2007. Recommendations for fatigue design of welded joints and components. IIW document XIII-2151-07 / XV1254-07. Paris, France.

Hughes, O. F., 1983. Ship Structural Design: A RationallyBased, Computer-Aided, Optimization Approach, John Wiley\&Sons, NY.

Paik J. K. \& Mansour A. E., 1995, A simple formulation for predicting the ultimate strength of ships, Journal of Marine Science and Technology Volume 1, Number 1, 52-62,

Radaj D. et al., 2006. Fatigue assessment of welded joints by local approaches (second edition). Cambridge: Abington Publishers,

Remes, H. et al., 2009. Rational models to assess fatigue at the early design stage. EU FP6 project IMPROVE-Final Conference; 1:51- 52. Dubrovnik, Croatia.

Rigo, P., 2001. A module-oriented tool for optimum design of stiffened structures-Part I, Marine structures;

Rigo, P. \& Fleury, C., 2001. Scantling optimization based on convex linearizations and a dual approach-Part II. Marine Structures;

Rigo, P., 2005. Differential Equations of Stiffened panels of Ship Structures and Fourier Series Expansions. Ship Technology Research; 82-100.

U.K. department of Energy, 1993. Proposed Revision to Fatigue Guidance 